\title{
Kinetic Study of the Adsorption of Polyphenols from Olive Mill Wastewater onto Natural Clay: Ghassoul
}

\author{
Safae Allaoui $\mathbb{D}^{1},{ }^{1}$ Mohammed Naciri Bennani, ${ }^{1}$ Hamid Ziyat ${ }^{(D)},{ }^{1}$ Omar Qabaqous, \\ Najib Tijani, ${ }^{2}$ and Najim Ittobane ${ }^{3}$ \\ ${ }^{1}$ Laboratory of Chemistry-Biology Applied to the Environment, Research Team "Applied Materials and Catalysis", \\ Chemistry Department, Faculty of Sciences, Moulay-Ismaïl University, BP. 11201-Zitoune, Meknes 50000, Morocco \\ ${ }^{2}$ Research Team "Membrane Materials and Separation Processes," Chemistry Department, Faculty of Science, \\ Moulay-Ismaïl University, BP. 11201-Zitoune, Meknes 50000, Morocco \\ ${ }^{3}$ Research Team "Biomolecular and Macromolecular Chemistry," Chemistry Department, Faculty of Science, \\ Moulay-Ismaíl University, BP. 11201-Zitoune, Meknes 50000, Morocco
}

Correspondence should be addressed to Safae Allaoui; allaouisafae@gmail.com

Received 7 December 2019; Accepted 11 March 2020; Published 25 April 2020

Guest Editor: Lisa Yu

Copyright (C) 2020 Safae Allaoui et al. This is an open access article distributed under the Creative Commons Attribution License, which permits unrestricted use, distribution, and reproduction in any medium, provided the original work is properly cited.

The aim of this study is based on natural clay as an adsorbent in the elimination of polyphenols from olive mill wastewater (OMW). This clay was analyzed using XRD, SEM/EDX, FTIR, surface area measurement (BET method), thermal analysis (TGA/ DTA), and X-ray fluorescence (XRF) and then used in adsorption experiments. The results reveal that the best quantity of adsorption of polyphenols is $161 \mathrm{mg} / \mathrm{g}$ at the temperature of $25^{\circ} \mathrm{C}$, but they decrease at $35^{\circ} \mathrm{C}$ and $45^{\circ} \mathrm{C}$. A great agreement with pseudo-second-order and Freundlich model is represented by kinetic and isotherms models, and several parameters such as $\Delta G^{0}$, $\Delta S^{0}$, and $\Delta H^{0}$ were determined using the thermodynamic function relationship.

\section{Introduction}

The olive mill wastewaters (OMWs) from two-phase extraction systems are deemed to be one of the main environmental problems in region Fes-Meknes, Morocco (Figure 1), due to presence of toxic elements such as polyphenols. In 2016, Morocco generated 4000 to 5000 tonnes of OMW diverse in the rivers [1] because we used greater quantities of water which generate large volumes of the latter [2].

OMW is an environmental threat, and it became a problem that needs to be solved by the olive industry [3]. The composition of OMW may vary significantly depending on several factors: climate conditions, olive storage period, extraction process, and period of production [4].

Many physicochemical and biological techniques have been developed to treat OMW. These methods include coagulation/flocculation [5, 6], oxidation, ozonation [7], and membrane filtration $[3,7,8]$. Despite the availability of the processes above, the adsorption method is most extensively employed for treatments of the OMW.
For instance, Curi and Velioglu [9] and Azzam [10] utilized activated charcoal and natural clay for adsorption of hydroxytyrosol and other phenolic mixes from OMW.

The goal of this research is the elimination of OMW polyphenols onto a low-cost clay called ghassoul and the characterization of this material. For this purpose, the quantity of polyphenols retained has been determined at the equilibrium. The isotherms to Langmuir and Freundlich models have been described. Moreover, the kinetic of adsorption has been analyzed uses pseudo-first-order (PFO), pseudo-second-order (PSO), and Weber-Morris intraparticle diffusion (IPD) models.

\section{Materials and Methods}

2.1. Material. The material used is the commercial clay labelled "Ghassoul Chorafa Al Akhdar" without any further treatment, native from a site called "Ksabi" in the Province of Missour, East of Middle Atlas (Fez-Morocco). The particles of size $<63 \mathrm{~nm}$ are crushed and dried during 24 hours at $80^{\circ} \mathrm{C}$ 


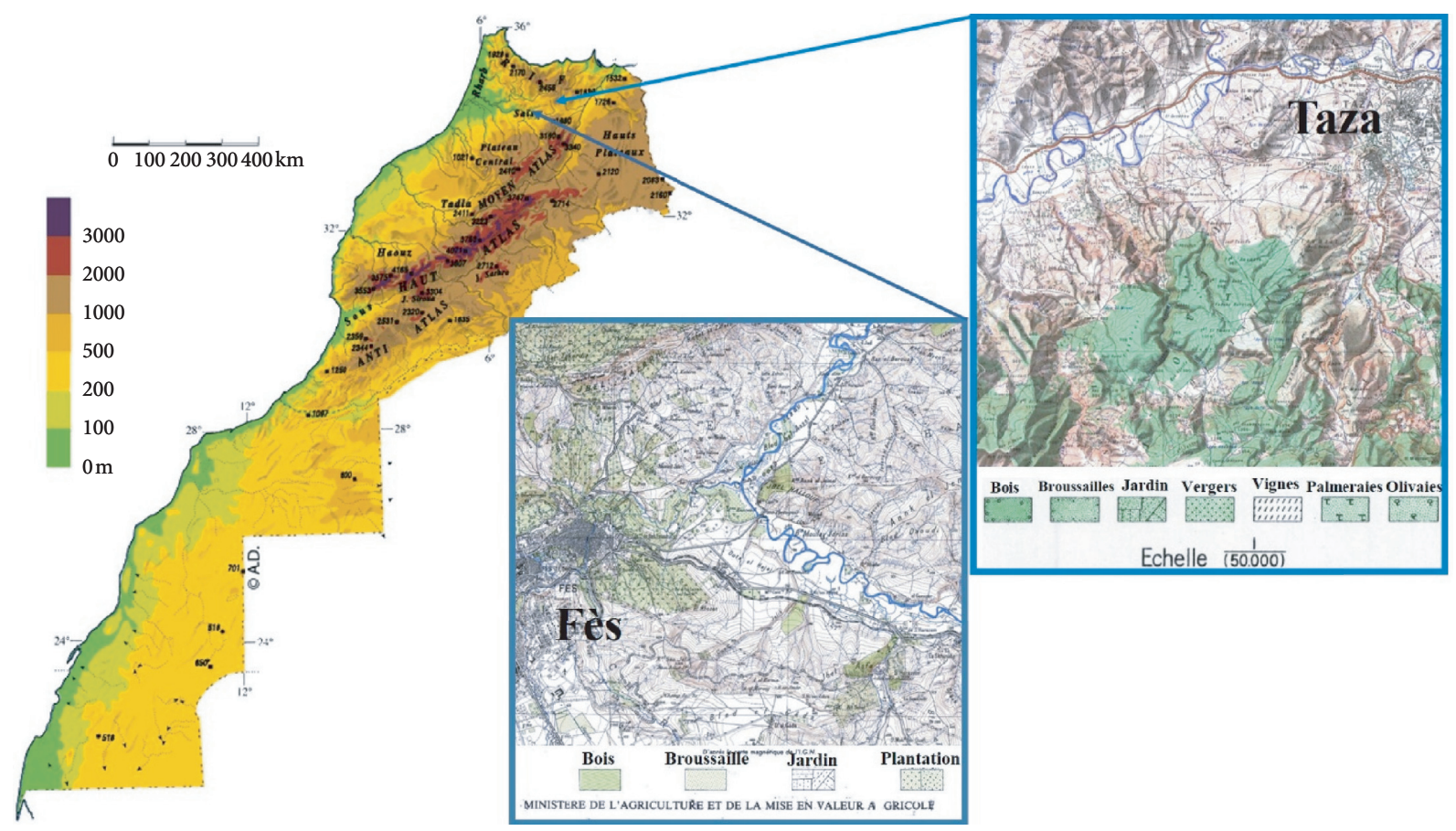

FIGURE 1: Geographical map of the origin of olive (taza) and sampling OMW (Fes), Morocco.

in the steam room. The prepared product was called Gh-B, referring to unprocessed ghassoul.

2.2. Olive Mill Wastewater and Pretreatment. The origin olive from Taza (Morocco) and the OMW was obtained from a two-phase discontinuous extraction factory in the Fes-Meknes region (Morocco) on 20 November 2018. The gathered OMW was kept in separate plastic containers until use and then treated under nitrogen stream to remove dissolved oxygen to protect polyphenols. The sample obtained was then filtered and conserved to prepare a stock solution for kinetic study.

\subsection{Physical, Chemical, and Mineralogical Characterisation.} The Gh-B was characterized by physicochemical techniques (XRD, FTIR, BET, DTA/TGA, SEM, EDX, and XRF).

For X-ray diffraction analysis, the Philips PW 1800 instrument has been utilized. The quickening voltage was $40 \mathrm{kV}$, the current was $20 \mathrm{~mA}$, and the copper $\mathrm{K} \alpha$ radiation was $\lambda=1.5418 \AA$. The spectra of the different samples were registered in an interval of $2 \theta\left(5^{\circ}-70^{\circ}\right)$ with an accurate addition of $0.04^{\circ}$.

FTIR investigation was directed by using Fourier Transform Infrared Spectrometer (JASCO 4000), out fitted in with a detector (TGS) and a ceramic source isolated by an optical framework utilizing an interferometer of Michelson. FTIR spectra are extended somewhere in the range of 4.000 and $400 \mathrm{~cm}^{-1}$.

The Micromeritics ASAP 2010 Gas Sorption System was used to measure the surface area, and both methods of BET and $\mathrm{BJH}$ were utilized for determination of the specific surface and the pore size.
Thermogravimetric (TGA-DTA) investigation was completed by using Shimadzu TA-60 type contraption, working under air with a direct warming rate of $10^{\circ} \mathrm{C} \cdot \mathrm{min}^{-1}$ from surrounding temperature to $600^{\circ} \mathrm{C}$.

The technique of SEM-EDX was utilized to determine the morphology and elemental composition of the Gh-B.

The $\mathrm{Gh}-\mathrm{B}$ dried at $105^{\circ} \mathrm{C}$ was analyzed by using X-ray fluorescence Philips PW 1666 type to determine the chemical composition, such as $\mathrm{P}_{2} \mathrm{O}_{5}, \mathrm{Al}_{2} \mathrm{O}_{3}, \mathrm{MgO}, \mathrm{Fe}_{2} \mathrm{O}_{3}$, $\mathrm{BaO}$, and $\mathrm{SiO}_{2}$.

2.4. Kinetic of Adsorption of Polyphenols from OMW onto Gh-B. Adsorption tests were done in black bottles to avoid the degradation of polyphenols. $50 \mathrm{mg}$ of $\mathrm{Gh}-\mathrm{B}$ with $50 \mathrm{~mL}$ of OMW was diluted in water (starting focus $C_{0}=30 \mathrm{mg} \cdot \mathrm{L}^{-1}$ ). The blends were waved at temperatures of $25^{\circ} \mathrm{C}, 35^{\circ} \mathrm{C}$, and $45^{\circ} \mathrm{C}$ during different times $(20 \mathrm{~min}$ to $180 \mathrm{~min})$. After each time, the blend is segregated by centrifugation at $3400 \mathrm{rpm}$ for $8 \mathrm{~min}$, and the supernatant was examined for determination of total polyphenols utilizing the Folin-Ciocalteu [11] technique and analyzed by UV-Vis spectroscopy. The absorbance at the wavelength of $760 \mathrm{~nm}$ was determined to calculate the leftover concentration of polyphenols $\left(C_{\mathrm{e}}\right.$, $\mathrm{g} \cdot \mathrm{L}^{-1}$ ), and amount of polyphenols adsorbed at equilibrium time $\left(q_{\mathrm{e}}\right.$, in $\left.\mathrm{mg} \cdot \mathrm{g}^{-1}\right)$ was calculated utilizing the following equation [12]:

$$
q_{\mathrm{e}}=\frac{\left(C_{0}-C_{\mathrm{e}}\right) \times V}{m}
$$

where $C_{0}$ is the initial concentration of polyphenols, $C_{\mathrm{e}}$ is the leftover concentration of polyphenols which are expressed by $\mathrm{g} \cdot \mathrm{L}^{-1}, m(\mathrm{mg})$ is the lump of Gh-B, and $V(\mathrm{~mL})$ is the volume of OMW diluted. 
The adsorption isotherms were done under identical conditions from those of the adsorption kinetic utilizing a larger concentration from 0 to $58 \mathrm{mg} \cdot \mathrm{L}^{-1}$ of polyphenols. The solutions were mixed for 3 hours until the equilibrium time was attained and then centrifuged. The determination of residual concentrations and the adsorbed amounts was done using (1).

2.5. Theoretical Background. We present in this part the expressions utilized to represent the kinetic and isotherms of the examined models.

\subsection{Modelling of Kinetic Studies}

2.6.1. Kinetic of PFO. The kinetic model Lagergren [13] of pseudo-first-order (PFO) is represented by the following equation:

$$
\ln \left(q_{\mathrm{e}}-q_{t}\right)=\ln q_{\mathrm{e}}-K_{1} t
$$

where $q_{t}$ is the capacity adsorbed at time $t ; q_{\mathrm{e}}$ is the capacity adsorbed at balanced, which are expressed by $\mathrm{mg}^{-1}$; and $K_{1}$ $\left(\mathrm{min}^{-1}\right)$ is the speed constant of PFO. $K_{1}$ and $q_{\mathrm{e}}$ can be determined by plotting $\ln \left(q_{\mathrm{e}}-q_{t}\right)$ versus the time $t$.

2.6.2. Kinetic of PSO. The expression of the pseudo-secondorder (PSO) model $[13,14]$ is represented by the following equation:

$$
\frac{t}{q_{t}}=\frac{1}{K_{2} \times q_{\mathrm{e}}^{2}}+\frac{t}{q_{\mathrm{e}}},
$$

where $K_{2}\left(\mathrm{~g} \cdot \mathrm{mg}^{-1} \cdot \mathrm{min}^{-1}\right)$ is the speed constant for the PSO and $q_{\mathrm{e}}$ is the quantity of polyphenols adsorbed at the balanced $\left(\mathrm{mg}^{-1}\right)$. The slope and the $y$-intercept are utilized to calculate $K_{2}$ of PSO and $q_{\mathrm{e}}$.

2.6.3. Model of IPD. The determination of intraparticle diffusion models is done using equation (4) (Weber-Morris equation) $[14,15]$. This model is used to determine the limiting step in the adsorption mechanism:

$$
q_{t}=K_{\mathrm{d}} \times t^{1 / 2}+C,
$$

where $K_{\mathrm{d}}$ is the IPD constant in $\mathrm{mg} \cdot \mathrm{g}^{-1} \cdot \mathrm{min}^{-1 / 2}$ and $C$ represents the value of the thickness of the boundary layer. They can both be determined from slope and the $y$-intercept (equation (4)).

2.7. Adsorption of Isotherm Studies. In the literature, various models have been published to compare experimental and theoretical data of adsorption isotherms. Freundlich and Langmuir models were utilized to describe isotherm adsorption.

2.7.1. Langmuir Model. The nonlinear shape of the Langmuir model [14] is expressed by the following equation:

$$
\frac{q_{\mathrm{e}}}{q_{\max }}=\frac{\left(K_{\mathrm{L}} \times C_{\mathrm{e}}\right)}{\left(1+K_{\mathrm{L}} \times C_{\mathrm{e}}\right)},
$$

where $K_{\mathrm{L}}$ is the Langmuir constant $\left(\mathrm{L} \cdot \mathrm{mg}^{-1}\right), C_{\mathrm{e}}$ is the equilibrium polyphenol concentration $\left(\mathrm{mg} \cdot \mathrm{L}^{-1}\right), q_{\mathrm{e}}$ is the adsorption capacity of polyphenols at equilibrium $\left(\mathrm{mg}^{-1} \mathrm{~g}^{-1}\right)$, and $q_{\mathrm{m}}$ is the maximum adsorption amount for a monolayer $\left(\mathrm{mg} \cdot \mathrm{g}^{-1}\right)$. Another parameter labelled separation factor $\left(R_{\mathrm{L}}\right)$ $[16,17]$ is expressed in the following equation:

$$
R_{\mathrm{L}}=\frac{1}{1+K_{\mathrm{L}} \times C_{0}},
$$

where $C_{0}$ is the initial concentration of the adsorbate $\left(\mathrm{mg} \cdot \mathrm{L}^{-1}\right) . R_{\mathrm{L}}$ is the factor of separation which allows to check whether the isotherm is favorable or not provided that if the value of $R_{\mathrm{L}}$ is between 0 and 1 , it confirms the validity of the Langmuir model; when $R_{\mathrm{L}}$ is close to 1 or 0 , it signifies that the isotherms are linear and irreversible, respectively, and if $R_{\mathrm{L}}$ is upper to 1 , it indicate that isotherm is unfavourable $[16,17]$.

2.7.2. Freundlich Model. The nonlinear type of the Freundlich model $[15,18]$ can be calculated by the following equation:

$$
q_{\mathrm{e}}=K_{\mathrm{F}} \times C_{\mathrm{e}}^{1 / n}
$$

where $q_{\mathrm{e}}$ is the equilibrium polyphenol concentration on the ghassoul, $C_{\mathrm{e}}$ is the equilibrium polyphenol concentration of solution, $K_{\mathrm{F}}$ is the Freundlich constant, and $n$ is the adsorption intensity characterizing the affinity of the pollutant for the adsorbent; when $n$ is close to 1, it signifies a chemical adsorption process, and when $n$ is greater than 1 , it indicates a physical adsorption mechanism.

2.7.3. Thermodynamic Parameters of Adsorption. The enthalpy $\left(\Delta H^{0}\right)$, free energy $\left(\Delta G^{0}\right)$, and entropy $\left(\Delta S^{0}\right)$ thermodynamic parameters are calculated by the following relations [19]:

$$
\begin{aligned}
& \Delta G^{0}=-R T \ln (K), \\
& \ln K=\frac{\Delta S^{0}}{R}+\frac{\Delta H^{0}}{R T},
\end{aligned}
$$

where $K_{\mathrm{C}}$ is the equilibrium constant defined as follows:

$$
K_{\mathrm{C}}=\frac{C_{\mathrm{ads}}}{C_{0}}=\frac{\left(C_{\mathrm{e}}-C_{0}\right)}{C_{\mathrm{e}}},
$$

in which $C_{\text {ads }}$ is the adsorbed concentration $(\mathrm{g} / \mathrm{L})$ and $C_{0}$ is the initial concentration of polyphenols in OMW $(\mathrm{g} / \mathrm{L})$.

\section{Results and Discussion}

\subsection{Physicochemical Characterization of $G$ h-B}

3.1.1. XRD Study. XRD analyses (Figure 2) showed that Gh$B$ consists of three phases of clay: 


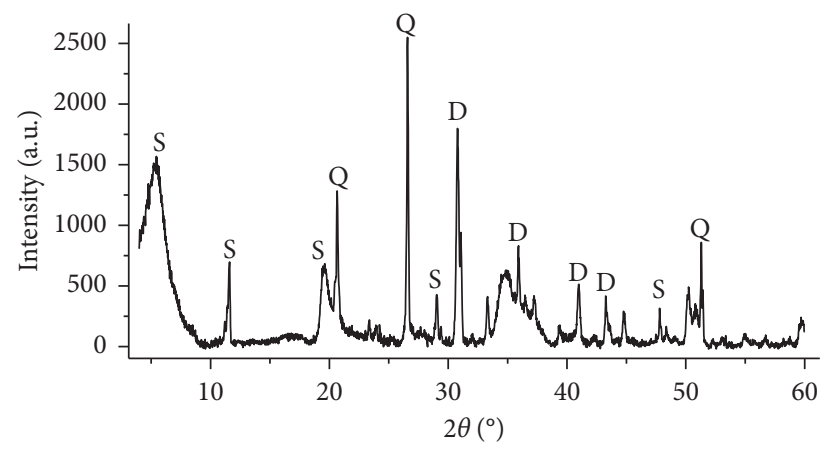

S: Stevensite
D: Dolomite
Q: Quartz

FIgURE 2: X-ray diffraction patterns of Gh-B.

TABle 1: Chemical composition of Gh-B.

\begin{tabular}{lccccccccc}
\hline Name of compound & $\mathrm{P}_{2} \mathrm{O}_{5}$ & $\mathrm{Fe}_{2} \mathrm{O}_{3}$ & $\mathrm{SiO}_{2}$ & $\mathrm{BaO}$ & $\mathrm{MgO}$ & $\mathrm{MO}$ & $\mathrm{Al}_{2} \mathrm{O}_{3}$ & \\
\hline \% of oxide & 0.0325 & 1.544 & 42.965 & 0.0314 & 13.532 & 0.290 & 2.514 & $\mathrm{Zn}$ & $\mathrm{Pb}$ \\
\hline Element in & $\mathrm{S}$ & $\mathrm{Ca}$ & $\mathrm{F}$ & $\mathrm{Sn}$ & $\mathrm{As}$ & $\mathrm{Cu}$ & $\mathrm{Ag}$ \\
\hline$(\%)$ & 4.303 & 6.770 & 0.940 & $<\mathrm{LD}$ & $<\mathrm{LD}$ & 0.009 & 0.006 & 0.006 & $<\mathrm{LD}$ \\
\hline
\end{tabular}

LD: limit of detection.

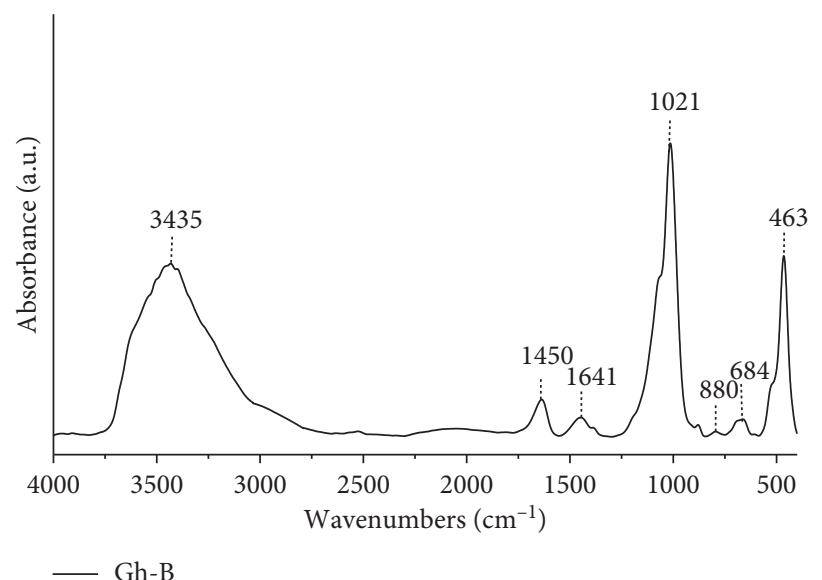

FIgURE 3: FTIR spectra of Gh-B.

(i) Stevensite (S) observed at the $2 \theta=5.70^{\circ}, 11.61^{\circ}$, $19.33^{\circ}, 29.43^{\circ}, 33.40^{\circ}$, and $44.84^{\circ}$

(ii) Dolomite (D) observed at the $2 \theta=30.83^{\circ}, 34.58^{\circ}$, $41.03^{\circ}$, and $35.22^{\circ}$

(iii) Quartz (Q) observed at the $2 \theta=20.73^{\circ}, 26.52^{\circ}$, and $53.70^{\circ}$

One also notices the presence of free silica in the shape of quartz and dolomite in very small amount. On the contrary, the stevensite and magnesia poles of the smectites series are dominant in the Gh-B. These outcomes are congruent with those obtained in the literature [19-21].

3.1.2. XRF Analysis. XRF was carried out to identify the chemical composition of the minerals present in the Gh-B.
The information given in Table 1 demonstrates that the magnesium and silica oxides are available in a large quantity; the presence of alumina $\left(\mathrm{Al}_{2} \mathrm{O}_{3}\right)$ is very important, and other elements are present in trace quantity. These results are in agreement with the XRD results and those cited by other authors such as Elass et al. and Ajbary et al. [20, 21].

3.1.3. FTIR Analysis. The spectra of natural clay (Gh-B) demonstrate a large absorption band at $3437 \mathrm{~cm}^{-1}$ corresponding to the $\mathrm{OH}$-stretching vibration of the water molecules. The bending mode of the interlayer and/or adsorbed water appears around $1641 \mathrm{~cm}^{-1}$. The stretching vibrations anti-symmetric $\mathrm{C}-\mathrm{O}$ around $1450 \mathrm{~cm}^{-1}$ show the presence of the carbonate anions $\left(v_{\text {as }}\left(\mathrm{CO}_{3}^{-2}\right)\right)$ inside walls. Both vibrations of $\left(v_{\mathrm{s}}\left(\mathrm{CO}_{3}^{-2}\right)\right)$ and $\mathrm{Al}_{2} \mathrm{O}_{3}$ groups are 

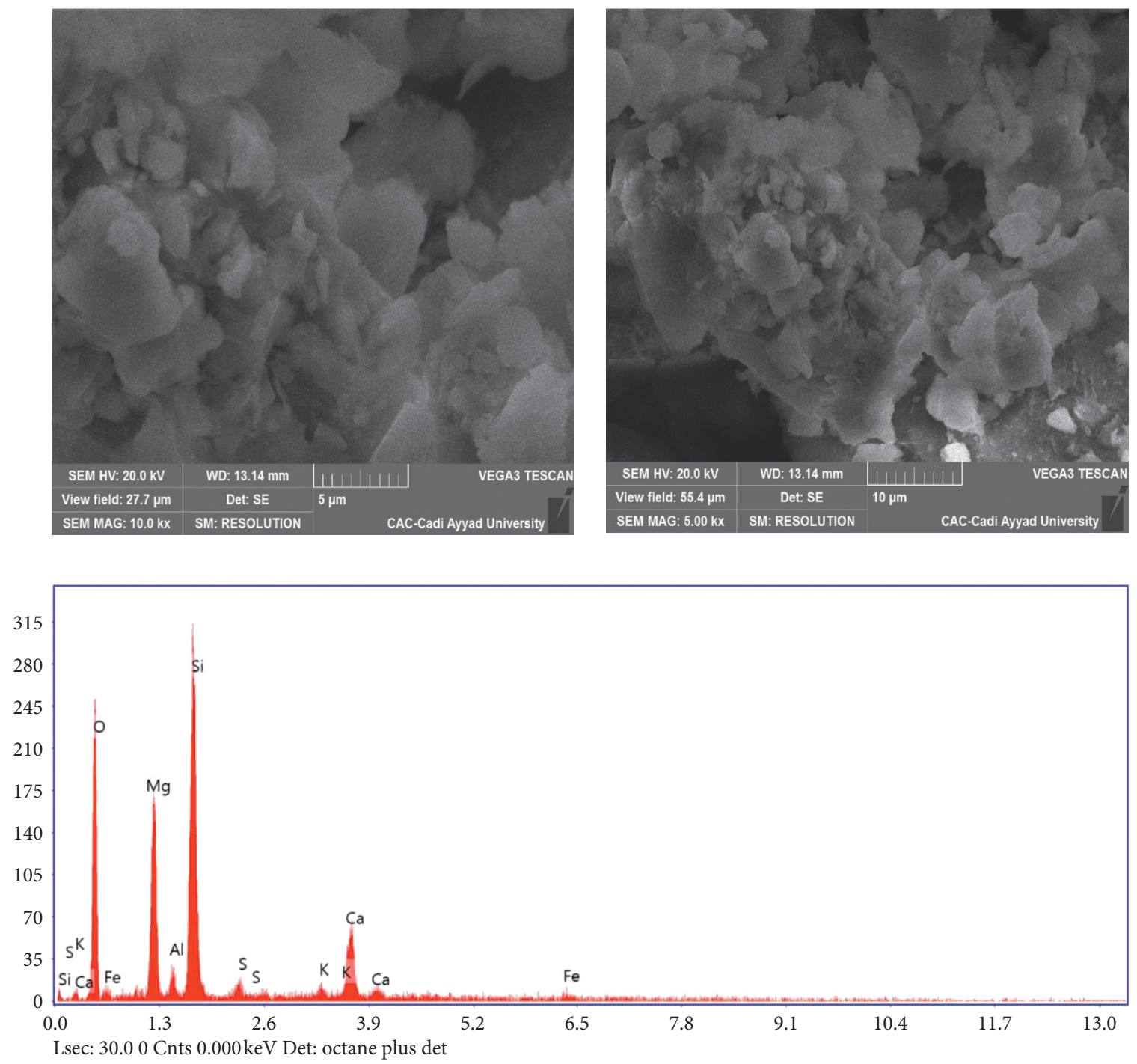

Figure 4: SEM images and EDX analysis of Gh-B.

TABle 2: Chemical elements of Gh-B and their \%.

\begin{tabular}{lcccccccc}
\hline Element & $\mathrm{O}$ & $\mathrm{Fe}$ & $\mathrm{Mg}$ & $\mathrm{Al}$ & $\mathrm{Si}$ & $\mathrm{S}$ & $\mathrm{K}$ & $\mathrm{Ca}$ \\
\hline$\%$ masses & 47.9 & 4 & 13.8 & 1 & 23.8 & 0.7 & 0.6 & 8.2 \\
\hline
\end{tabular}

observed at $880 \mathrm{~cm}^{-1}$. The bands which appear around 1021 , 684 , and $463 \mathrm{~cm}^{-1}$ are attributed to the vibrations of the $\mathrm{SiO}_{2}$ group (Figure 3).

3.1.4. SEM/EDX and BET Analysis. SEM micrograph of Gh$\mathrm{B}$ (Figure 4) shows that the morphology of the Gh-B is close to hectorite, and the particles from different sizes have the appearance of sheets which oriented parallel to each other, as indicated by Caillere and Henin [22].

The chemical elements contained in natural clay (GhB) were detected by EDX analysis, and the results show that Gh-B has a higher percentage of silica (Table 2) mainly due to the presence of majority of quartz followed by magnesia. These results are in agreement with XRD and $\mathrm{XRF}$ analysis.
Table 2 gives the chemical elements and their mass percentages determined by the EDX analysis.

The nitrogen adsorption/desorption isotherms of Gh-B show that, according the IUPAC classification, isotherm obtained is type IV, characteristic of solid mesoporous with onset the hysteresis of $\mathrm{H} 3$ type. After calculating using the BET method, the specific surface is $296 \mathrm{~m}^{2} / \mathrm{g}$.

The pore size distribution is determined from desorption isotherm by the BJH method, shown in Figure 5 . This latter shows that the pore diameter is in the order of $73 \AA$ and thus confirms the mesoporosity of the structure of the Gh-B.

3.1.5. Thermal Analysis (DTA/TGA). TGA/DTA thermogram (Figure 6) shows that the breakdown of Gh-B is done on three exothermic steps and one endothermic step: 


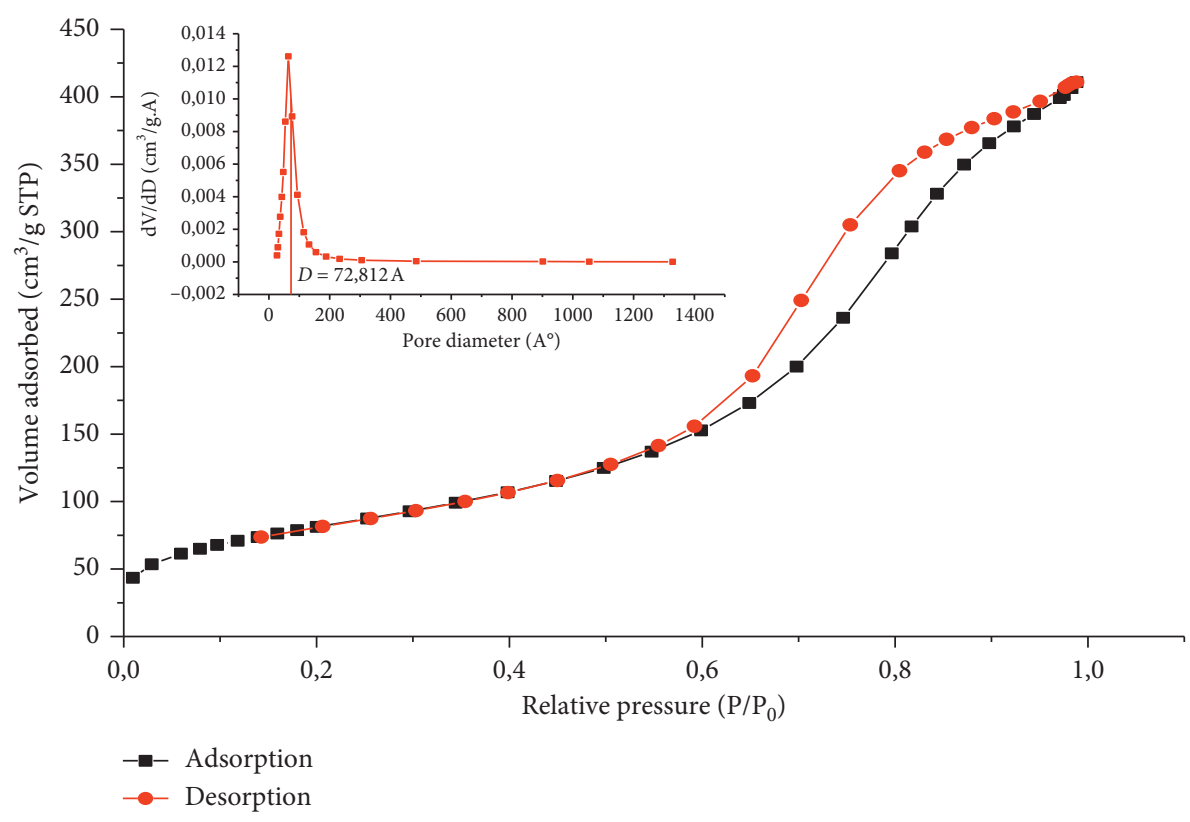

FIGURE 5: $\mathrm{N}_{2}$ adsorption/desorption isotherms of Gh-B.

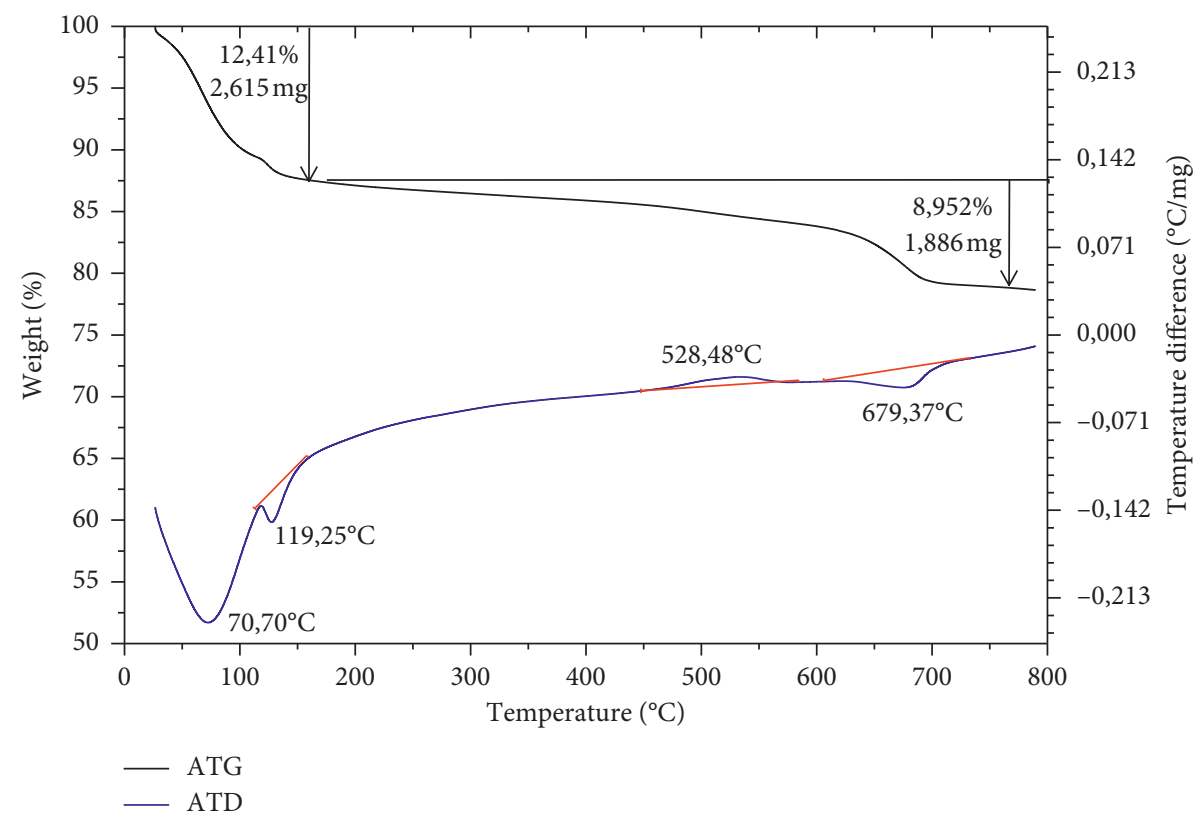

Figure 6: DTA and TGA plots of Gh-B.

(i) First degradation step with loss of mass on the order of $12 \%$ due to the removal of water molecules infirm bound or adsorbed on external faces of the crystals. This step manifests itself by two distinct endothermic peaks on curve ATD at two temperatures $70.70^{\circ} \mathrm{C}$ and $128.95^{\circ} \mathrm{C}$, respectively.

(ii) Second loss of almost $8.95 \%$ mass at $679.37^{\circ} \mathrm{C}$ (ATD), which is manifested by wide and asymmetric peak corresponding to decomposition of the early mixed carbon of magnesia and the calcium. (iii) Exothermic pic around $528^{\circ} \mathrm{C}$ corresponding to allotropic transformation of the stevensite in enstatite.

That transformation of stevensite in enstatite is represented by the following equation:

$$
\begin{aligned}
2 \mathrm{Mg}_{3} \mathrm{Si}_{4} \mathrm{O}_{10}(\mathrm{OH})_{2} \cdot n \mathrm{H}_{2} \mathrm{O} \longrightarrow & 3\left(\mathrm{MgSiO}_{3}+\mathrm{MgO}\right)+5 \mathrm{SiO}_{2} \\
+ & 2(n+1) \mathrm{H}_{2} \mathrm{O} .
\end{aligned}
$$




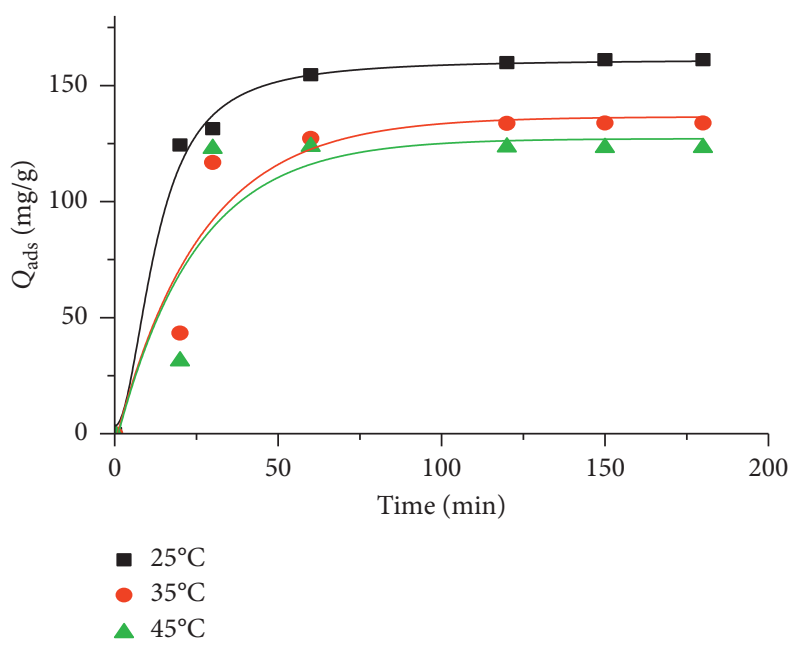

FIgURE 7: Various adsorption kinetic according to time of three temperatures.

3.2. Kinetics Adsorption. Figure 7 demonstrates that the quantity of polyphenols adsorbed at different temperatures is in the order $161 \mathrm{mg} / \mathrm{g}$ and considered important because of the high specific surface area $\left(296 \mathrm{~m}^{2} \cdot \mathrm{g}^{-1}\right)$ of Gh-B. The curves demonstrate that the adsorption kinetics is very quick at the start, due to the presence of the active sites at the start of adsorption, and the equilibrium was established after $2 \mathrm{~h}$ (about $60 \mathrm{~min}$ at $25^{\circ} \mathrm{C}$ ). The quantities of polyphenols adsorbed onto Gh-B diminished from 161 to $123 \mathrm{mg} \cdot \mathrm{g}^{-1}$ when the temperature increases from $25^{\circ} \mathrm{C}$ to $45^{\circ} \mathrm{C}$, indicating that the temperature higher than $25^{\circ} \mathrm{C}$ destabilizes the force of adsorption and also decreases the interaction between Gh-B and polyphenols, and therefore, the adsorption process is exothermic. The same observation was found by De Chimie et al., works of adsorption of polyphenols from OMW by pomace olive which is utilized as an active carbon [23].

The plots of $\ln \left(q_{\mathrm{e}}-q_{t}\right)$ and $t / q_{t}$ according to time (equations (2) and (3), respectively) are obtained in Figures 8 (a) and $8(\mathrm{~b})$, respectively. We can wind up that polyphenols are adsorbed onto Gh-B and excellently followup the PSO model (Figure 8(a)). This is endorsed by these adsorbed quantities determined theoretically $\left(q_{\mathrm{th}}\right)$ and are very near to those obtained experimentally $\left(q_{\exp }\right), R^{2}=0.99$ (Table 3).

In this study, we notice that when the temperature of the solution raises, the apparent constant of the PSO speed $K_{2}$ increased probably due to chemisorption phenomena. The same observation has been obtained in the adsorption of phenolic compounds from OMW on orange peel [24], on active carbon [25-28], onto resin [29], on onion [30], in removal of basic yellow cationic dye, [21] and in methyl violet by the same adsorbent (ghassoul) [20].

3.2.1. IPD. The plot of the adsorbed quantity $q_{t}$ versus $t^{1 / 2}$ shows that polyphenols are adsorbed in two steps (Figure 9). The first one is quick; this is due to the transfer of polyphenols from OMW to the outside of the adsorbent. The second step is typified by a slight evolution to equilibrium, and it represents interaction between ghassoul and polyphenols. These results validate an adsorption according to a kinetic of the PSO. However, the values of constant $C$ are different to 0 (Table 4) that shows the rate of polyphenol adsorption onto Gh-B is not controlled only by IPD step. This results is an agreement with Valderrama et al. andLavinia et al. [31, 32].

3.2.2. Study of Activation Energy $E_{a}$. The tracing of $\ln K_{2}$ as function to $1 / T$ allows to determine activation energy $E_{\mathrm{a}}$ from the slope of the equation line Arrhenius. Figure 10 shows that the experimental points give a line when $R^{2}$ is very near to 1 . The value of activation energy $(90.622 \mathrm{~kJ} / \mathrm{mol})$ given by the slope of the Arrhenius plot demonstrates that the adsorption of polyphenols from OMW can be controlled by a chemisorption phenomenon. This phenomenon is confirmed by the obtained kinetic results. This is in accordance with the works of M. kessoum[33] in the investigation of adsorbed polyphenols on a commercial active carbon (Picachem 150), but it is in disagreement with the results of Senol et al. [28] in the kinetic studies of biophenol adsorption onto commercial activated carbon with different particle sizes and at varied temperature. They have found the physisorption phenomenon because the values of $E_{\mathrm{a}}$ are included between 27.22 and $33.76 \mathrm{~kJ} / \mathrm{mol}$.

3.3. Adsorption Isotherms. The curves of nonlinear transforms obtained by Langmuir and Freundlich models are shown in Figure 11, and the different parameters deduced from the two models are grouped in Table 5.

In Figure 11, it is clearly demonstrated that the adsorbed quantity of the polyphenols $q_{\max }$ increases when the initial polyphenol concentration $C_{0}$ grows until the saturation. Table 5 shows a good linear correlation coefficient $R^{2}$ close to 1 for both isotherms Langmuir and Freundlich.

However, the values $n$ from the Freundlich model for various temperatures (Table 5) are greater than 1 , and the values of $K_{\mathrm{F}}$ are large, indicating that the adsorption is favorable. For the Langmuir model, the values of $R_{\mathrm{L}}$ are 


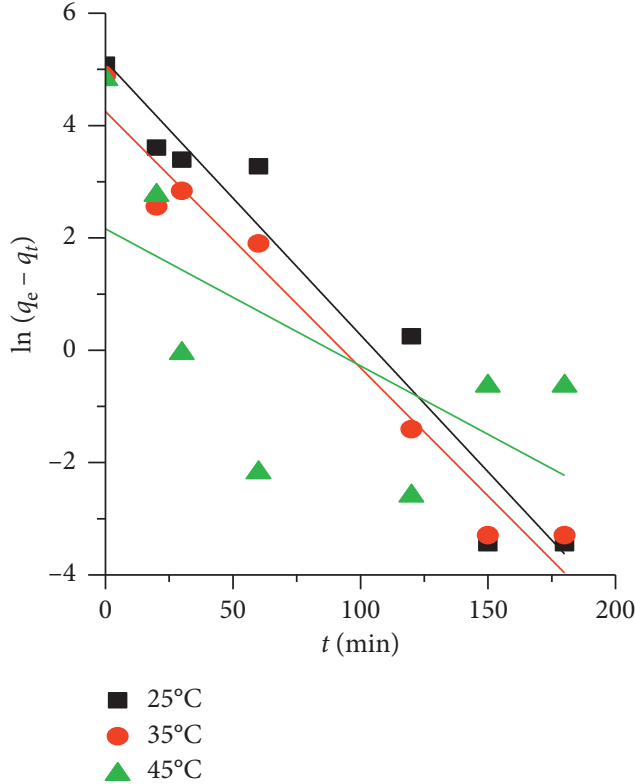

(a)

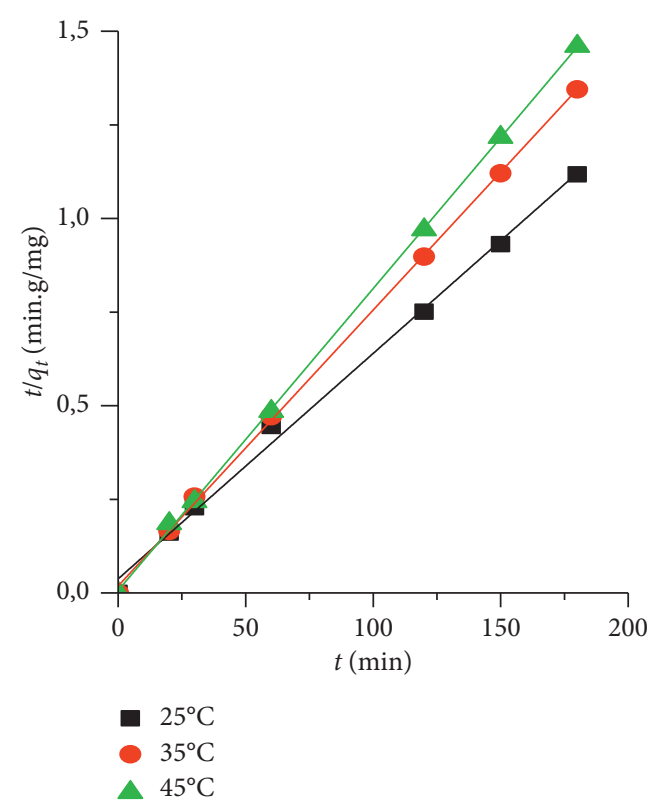

(b)

FIGURE 8: Linear portrayal of kinetic model of polyphenols adsorption onto Gh-B for both models (a) PFO and (b) PSO.

TABLE 3: PFO and PSO parameters.

\begin{tabular}{|c|c|c|c|c|c|c|c|}
\hline \multirow[b]{2}{*}{$T\left({ }^{\circ} \mathrm{C}\right)$} & \multicolumn{4}{|c|}{ PFO model } & \multicolumn{3}{|c|}{ PSO model } \\
\hline & $q_{\text {ads (exp) }}(\mathrm{mg} / \mathrm{g})$ & $K_{1}\left(\min ^{-1}\right)$ & $q_{\text {ads (theorique) }}(\mathrm{mg} / \mathrm{g})$ & $R^{2}$ & $q_{\text {ads (theorique) }}(\mathrm{mg} / \mathrm{g})$ & $K_{2}(\mathrm{~g} /(\mathrm{g} \cdot \mathrm{min})$ & $R^{2}$ \\
\hline 25 & 161 & 0.049 & 171 & 0.872 & 166.113 & 0.001 & 0.999 \\
\hline 35 & 134 & 0.046 & 70 & 0.920 & 135.685 & 0.003 & 0.999 \\
\hline 45 & 123 & 0.024 & 8.676 & 0.083 & 124.069 & 0.010 & 0.999 \\
\hline
\end{tabular}
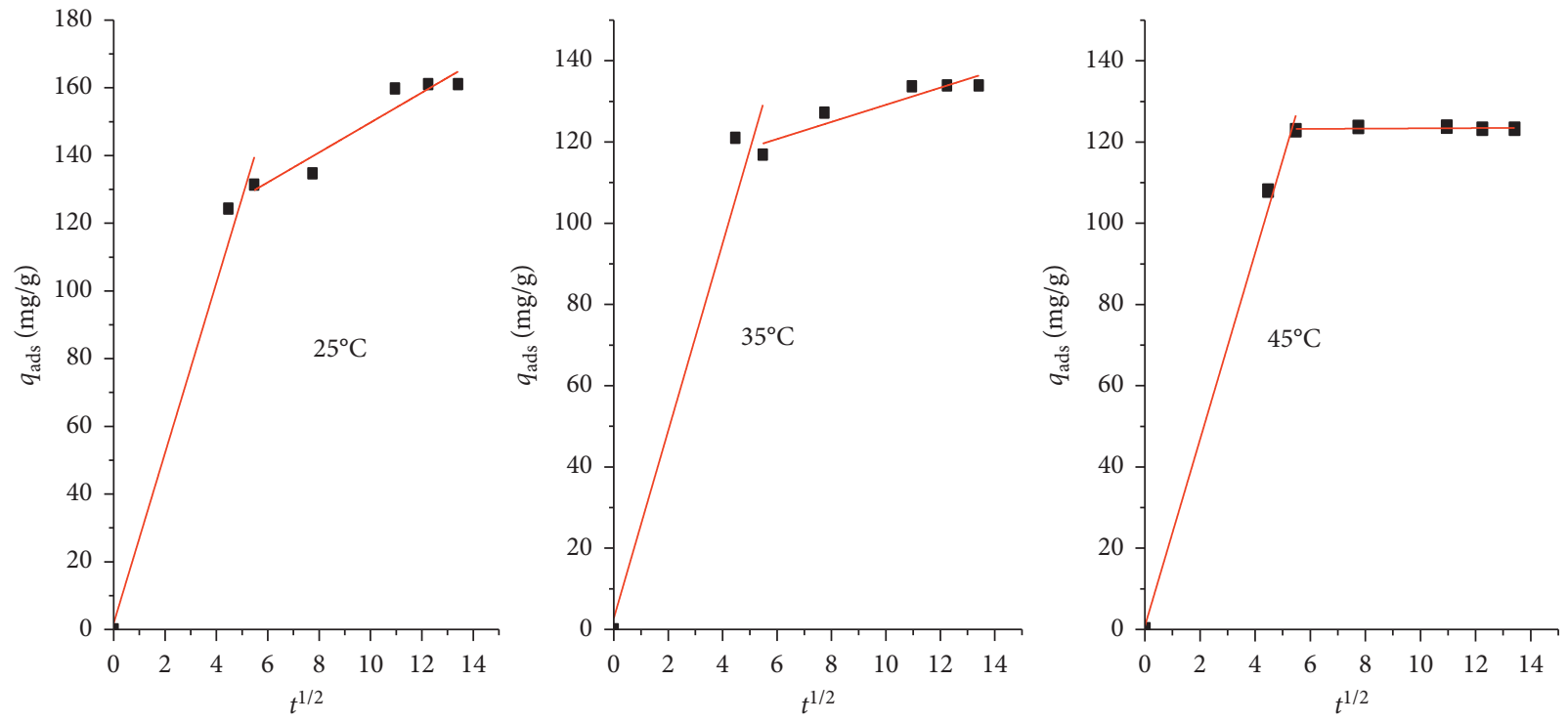

FIGURE 9: IPD plots for different temperatures.

TABle 4: Parameters of IPD.

\begin{tabular}{lccccr}
\hline & \multicolumn{1}{c}{ Step 1} & & \multicolumn{2}{c}{ Step 2} \\
$T\left({ }^{\circ} \mathrm{C}\right)$ & $C$ & $K_{\mathrm{d}}\left(\mathrm{g} \cdot \mathrm{mg}^{-1} \cdot \mathrm{min}^{-1 / 2}\right)$ & $R^{2}$ & $C$ & $K_{\mathrm{d}}\left(\mathrm{g} \cdot \mathrm{mg}^{-1} \cdot \mathrm{min}^{-1 / 2}\right)$ \\
\hline 25 & 1.83 & 25.14 & 0.99 & 105.55 & 4.41 \\
35 & 2.76 & 23.07 & 0.98 & 108.06 & 2.10 \\
45 & 0.82 & 22.95 & 0.99 & 123.04 & 0.97 \\
\hline
\end{tabular}




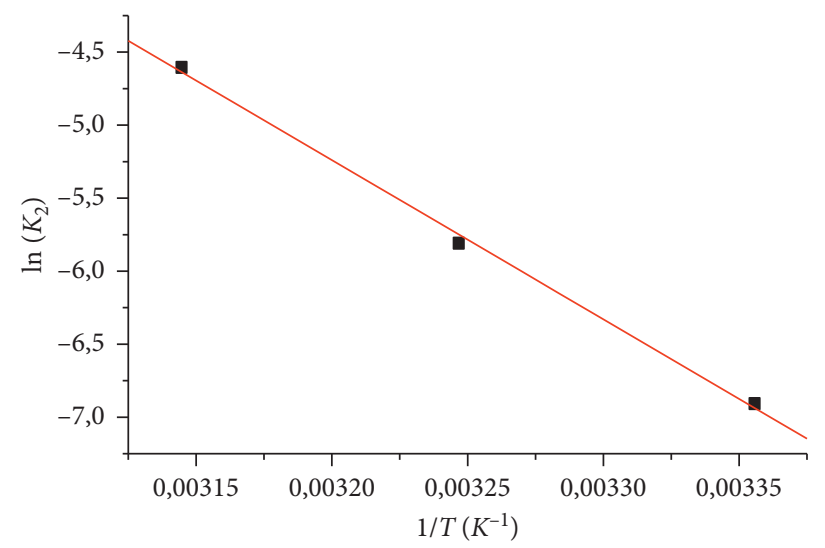

FIgURE 10: Arrhenius slope for adsorption of polyphenols.
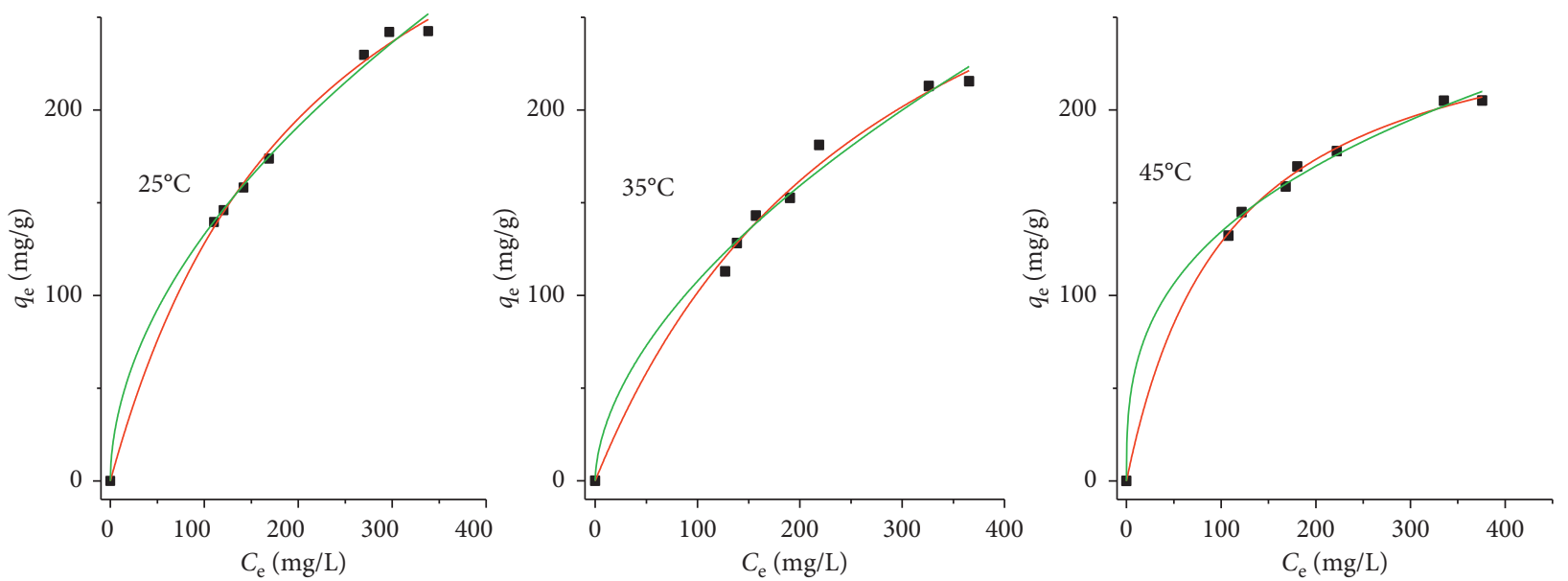

- Experimental point

_ Langmuir

— Freundlich

Figure 11: Adsorption isotherm for polyphenols onto ghassoul clay.

TABle 5: Parameters of adsorption isotherms.

\begin{tabular}{lcccccc}
\hline & \multicolumn{3}{c}{ Langmuir } & \multicolumn{2}{c}{ Freundlich } \\
$T\left({ }^{\circ} \mathrm{C}\right)$ & $q_{\max }(\mathrm{mg} / \mathrm{g})$ & $K_{\mathrm{L}}(\mathrm{mg} / \mathrm{g})$ & $R_{\mathrm{L}}$ & $R^{2}$ & $n$ & $K_{\mathrm{F}}(\mathrm{mg} / \mathrm{g})$ \\
\hline 25 & 411.91 & $4.51 \times 10^{-3}$ & 0.99 & 0.99 & 1.90 & 11.80 \\
35 & 397.78 & $3.40 \times 10^{-3}$ & 0.99 & 0.99 & 1.77 & 0.99 \\
45 & 265.81 & $9.38 \times 10^{-3}$ & 0.99 & 0.99 & 2.96 & 0.98 \\
\hline
\end{tabular}

near to 1 in the concentration domain from 0 to $58 \mathrm{mg} / \mathrm{L}$, but the amount of adsorbed $q_{\max }$ calculated from this model is much different from those found experimentally.

Therefore, the two models are favorable to describe the adsorption phenomena of polyphenols onto ghassoul clay, but Freundlich model is more suitable because the theoretical amount of polyphenols $\left(q_{\max }\right)$ calculated from the Langmuir model is very far to the experimental value for all temperatures. These results are similar to those obtained by Mounia et al. and Jedi et al. who worked on removing phenolic compound by adsorption onto wheat bran and bentonite, respectively $[33,34]$.

3.3.1. Thermodynamic Parameters. The negative value of $\Delta H^{0}(-0.14 \mathrm{~kJ} / \mathrm{mol})$ (Table 6) shows that the adsorption of polyphenols onto $\mathrm{Gh}-\mathrm{B}$ is an exothermic process in accordance with the kinetic studies ( $q_{\max }$ decreases with the increase in temperature). The order of the process is indicated by the negative value of $\Delta S^{0}(-46.25 \mathrm{~J} / \mathrm{K} \cdot \mathrm{mol})$. The adsorption process is spontaneous because of the negative 
TABLE 6: Thermodynamic parameters of adsorption of polyphenols onto Gh-B.

\begin{tabular}{lcccc}
\hline$T(\mathrm{~K})$ & $\Delta G^{0}(\mathrm{~kJ} / \mathrm{mol})$ & $\Delta S^{0}(\mathrm{~J} / \mathrm{K} \cdot \mathrm{mol})$ & $\Delta H^{0}(\mathrm{~kJ} / \mathrm{mol})$ & $R^{2}$ \\
\hline 298 & -3.11 & & & \\
308 & -1.18 & -46.25 & -0.14 & 0.99 \\
318 & -0.22 & & & \\
\hline
\end{tabular}

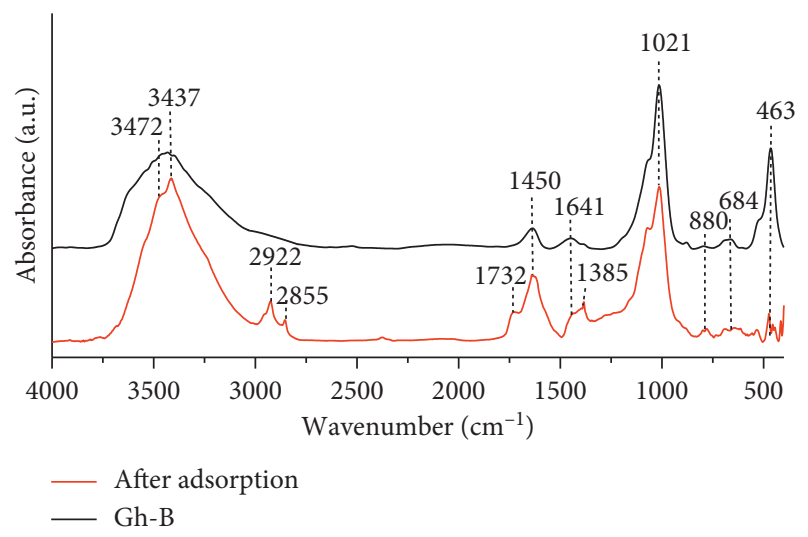

Figure 12: FTIR spectra of Gh-B before and after adsorption.

value of Gibbs free energy. These outcomes are identical to Makhlouf et al. in the study of the adsorption of phenolic compounds onto mesoporous material [35].

3.4. Analysis of the Adsorption by FTIR. The spectrum of Gh$B$ after adsorption in Figure 12 shows new bands of vibration. A shouldering to $3472 \mathrm{~cm}^{-1}$ and an intense band at $3437 \mathrm{~cm}^{-1}$ corresponding to hydroxyl stretching vibration of free and bonded - $\mathrm{OH}$ groups of the polyphenols, respectively. We also noted the presence of new bands at $2922 \mathrm{~cm}^{-1}$ and $2855 \mathrm{~cm}^{-1}$ corresponding to aromatic $\mathrm{C}-\mathrm{H}$ and other bands at 1732 and $1385 \mathrm{~cm}^{-1}$ attributed to the C-O group of polyphenols (Figure 12). These results indicate the presence of polyphenols and confirmed that these compounds are adsorbed onto ghassoul.

\section{Conclusion}

In this study, we are interested in testing the effectiveness of natural clay "Gh-B" in the elimination of polyphenols from olive mill wastewater (OMW).

The obtained results are as follows:

(i) The natural clay ghassoul is majority constituted of silica and magnesia. This result is in agreement with $\mathrm{XRD}, \mathrm{XRF}$, and SEM/EDX.

(ii) The quantity of the polyphenols adsorbed at different temperature has been of order $161 \mathrm{mg} / \mathrm{g}$, and it is considerably important because of high specific surface area $\left(296 \mathrm{~m}^{2} \cdot \mathrm{g}^{-1}\right)$ of Gh-B.

(iii) The examination of the adsorption kinetic of polyphenols onto Gh-B demonstrates that adsorption is done in two steps. The initial step is fast, and the balance comes at $2 \mathrm{~h}$ of contact. The next step is typified by slow evolution to equilibrium and adsorption kinetic realized at pseudo-second-order (PSO) model.

(iv) The experimental isotherms are preferentially described by the Freundlich model, and the thermodynamic study indicates that the adsorption of polyphenols was exothermic in nature $\Delta H^{0}<0$, ordered $\Delta S^{0}<0$, and spontaneous $\Delta G^{0}<0$.

(v) All outcomes demonstrated that ghassoul was an effective and feeble cost adsorbent for the elimination of polyphenols from "OMW".

\section{Data Availability}

The authors affirm that all information fundamental to the discoveries of this examination are completely accessible without limitation.

\section{Conflicts of Interest}

The authors declare that there are no conflicts of interest.

\section{Acknowledgments}

This work was done in the frame work of the project (PPR2), supported by Ministry of National Education, Professional Training, Higher Education and Scientific Research, Morocco (MENFPESRS), and National Center for Scientific and Technical Research/Rabat, Morocco (CNRST).

\section{References}

[1] B. Zghari, F. Benyoucef, and A. Boukir, "Impact environnemental des margines sur les eaux d'oued oussefrou: caracterisation physico-chimique et evaluation par chromatographie gazeuse couplee a la spectrometrie de masse ( CPG-SM ) the environmental impact of olive mill wastewater in oussefrou," American Journal of Innovative Research and Applied Sciences, vol. 2429-5396, pp. 276-291, 2018.

[2] A. L. I. Agoumi and A. Debbarh, Ressources en eau et bassins versants du Maroc: 50 ans de développement, Report prepared within the framework of the "Water: Management of scarcity" organized by the Association of Moroccan Engineers of Bridges and Roads, pp. 13-62, Marocco, 2005.

[3] B. Ibrahimoglu and M. Z. Yilmazoglu, "Disposal of olive mill wastewater with DC arc plasma method," Journal of Environmental Management, vol. 217, pp. 727-734, 2018.

[4] S. Dermeche, M. Nadour, C. Larroche, F. Moulti-mati, and P. Michaud, "Olive mill waste : biochemical characterization and valorization strategies," Process Biochemistry, vol. 48, no. 10, pp. 1532-1552, 2013.

[5] Ü. Tezcan Ün, S. Uğur, A. S. Koparal, and Ü. Bakir Öğütveren, "Electrocoagulation of olive mill wastewaters," Separation and Purification Technology, vol. 52, no. 1, pp. 136-141, 2006.

[6] T. Chatzistathis and T. Koutsos, "Olive mill wastewater as a source of organic matter, water and nutrients for restoration of degraded soils and for crops managed with sustainable systems," Agricultural Water Management, vol. 190, pp. 5564, 2016.

[7] C. H. Neoh, Z. Z. Noor, N. S. A. Mutamim, and C. K. Lim, "Green technology in wastewater treatment technologies: 
integration of membrane bioreactor with various wastewater treatment systems," Chemical Engineering Journal, vol. 283, pp. 582-594, 2016.

[8] T. Coskun, E. Debik, and N. M. Demir, "Treatment of olive mill wastewaters by nanofiltration and reverse osmosis membranes," Desalination, vol. 259, no. 1-3, pp. 65-70, 2010.

[9] D. V. K. Curi and S. G. Velioglu, "Treatment of olive oil production wastes treatment and disposal of liquid and solid industrial wastes," in Proceedings of the Third Turkish-German Environmental Engineering Symposium, pp. 189-205, Istanbul, Turkey, June 1979.

[10] M. O. J. Azzam, "Olive mills wastewater treatment using mixed adsorbents of volcanic tuff, natural clay and charcoal," Journal of Environmental Chemical Engineering, vol. 6, no. 2, pp. 2126-2136, 2018.

[11] V. L. Singleton, R. Orthofer, and R. M. Lamuela-Raventós, "[14] Analysis of total phenols and other oxidation substrates and antioxidants by means of folin-ciocalteu reagent," in Oxidants and Antioxidants Part A, vol. 299, pp. 152-178, Elsevier, Amsterdam, Netherlands, 1999.

[12] J. Huang, Y. Zhou, K. Huang, S. Liu, Q. Luo, and M. Xu, "Adsorption behavior, thermodynamics, and mechanism of phenol on polymeric adsorbents with amide group in cyclohexane," Journal of Colloid and Interface Science, vol. 316, no. 1, pp. 10-18, 2007.

[13] H. Yuh-Shan, "Citation review of lagergren kinetic rate equation on adsorption reactions," Scientometrics, vol. 59, no. 1, pp. 171-177, 2004.

[14] Y. S. Ho and G. McKay, "Pseudo-second order model for sorption processes," Process Biochemistry, vol. 34, no. 5, pp. 451-465, 1999.

[15] T. W. Weber and R. K. Chakravorti, "Pore and solid diffusion models for fixed-bed adsorbers," AIChE Journal, vol. 20, no. 2, pp. 228-238, 1974

[16] S. Muralidharan, K. Srikrishna, and S. Subramanian, "Optimized power generation using dynamic programming," International Energy Journal, vol. 8, pp. 217-224, 2007.

[17] K. R. Hall, L. C. Eagleton, A. Acrivos, and T. Vermeulen, "Pore- and solid-diffusion kinetics in fixed-bed adsorption under constant-pattern conditions," Industrial \& Engineering Chemistry Fundamentals, vol. 5, no. 2, pp. 212-223, 1966.

[18] Y. S. Ho and G. McKay, "Sorption of dye from aqueous solution by peat," Chemical Engineering Journal, vol. 70, no. 2, pp. 1227-1231, 1999.

[19] Y. Seki and K. Yurdakoç, "Equilibrium, kinetics and thermodynamic aspects of promethazine hydrochloride sorption by iron rich smectite," Colloids and Surfaces A: Physicochemical and Engineering Aspects, vol. 340, no. 1-3, pp. 143-148, 2009.

[20] K. Elass, A. Laachach, A. Alaoui, and M. Azzi, "Removal of methyl violet from aqueous solution using a stevensite-rich clay from Morocco," Applied Clay Science, vol. 54, no. 1, pp. 90-96, 2011.

[21] M. Ajbary, A. Santos, V. Morales-flórez, and L. Esquivias, "Removal of basic yellow cationic dye by an aqueous dispersion of Moroccan stevensite," Applied Clay Sciences, vol. 80-81, pp. 46-51, 2016.

[22] R. M. S. Caillere and S. Henin, Minéralogie des argiles: 2 Classification et omenclature, Masson, Paris, France, 1982.

[23] R. R. De Chimie, M. Ziati, F. Khemmari, and F. Didouche, "Removal of polyphenols from olive mill wastewater by adsorption on activated carbon prepared from peach stones," Revue Roumaine de Chimie, vol. 62, no. 11, pp. 865-874, 2017.
[24] H. Wazani, "Etude de traitement de margine par adsorption," pp. 56-57, Faculté des Sciences Dhar lmahraz, Fés, Marocco, 2017, Master.

[25] V. Fierro, V. Torné-Fernández, D. Montané, and A. Celzard, "Adsorption of phenol onto activated carbons having different textural and surface properties," Microporous and Mesoporous Materials, vol. 111, no. 1-3, pp. 276-284, 2008.

[26] M. Abdelkreem, "Adsorption of phenol from industrial wastewater using olive mill waste," APCBEE Procedia, vol. 5, pp. 349-357, 2013.

[27] A. Kumar, S. Kumar, and S. Kumar, "Adsorption of resorcinol and catechol on granular activated carbon: equilibrium and kinetics," Carbon, vol. 41, no. 15, pp. 3015-3025, 2013.

[28] A. Senol, İ.M. Hasdemir, B. Hasdemir, and İ. Kurda, "Adsorptive removal of biophenols from olive mill wastewaters (OMW) by activated carbon : mass transfer, equilibrium and kinetic studies," Asia-Pacific Journal of Chemical Engineering, vol. 12, no. 1, 2017.

[29] E. Ferrer-polonio, J. A. Mendoza-roca, A. Iborra-clar, and L. Pastor-alcañiz, "Adsorption of raw and treated by membranes fermentation brines from table olives processing for phenolic compounds separation recovery," Journal ChemicalTechnology and Biotechnology, vol. 91, no. 7, 2016.

[30] S. Kühn, H. R. Wollseifen, R. Galensa, N. Schulze-kaysers, and B. Kunz, "Adsorption of fl avonols from onion (Allium cepa $\mathrm{L}$ ) processing residues on a macroporous acrylic resin," Food Research International, vol. 65, 2014.

[31] C. Valderrama, J. Barios, M. Caetano, A. Farran, and J. Cortina, "Kinetic evaluation of phenol/aniline mixtures adsorption from aqueous solutions onto activated carbon and hypercrosslinked polymeric resin (MN200)," Reactive and Functional Polymers, vol. 70, pp. 142-150, 2010.

[32] L. Luvinia, L. Cocheci, R. Pode, and I. Hulka, "Phenol adsorption using Aliquat 336 functionalized Zn-Al layered double hydroxide," Separation and Purification Technology, vol. 196, pp. 82-95, 2018.

[33] M. Kessoum, V. Caqueret, O. Chedeville, B. Cagnon, S. Bostyn, and C. Porte, "Etude de la cinétique et de la thermodynamique d'adsorption de composés phénoliques en monosolutés et en mélange sur charbon actif," pp. 26-28, 2014.

[34] A. Mounia, A. Hafidi, L. Mandi, and N. Ouazzani, "Removal of phenolic compounds from olive mill wastewater by adsorption onto wheat bran," Desalination and Water Treatment, vol. 52, no. 13, pp. 1-11, 2015.

[35] M. Makhlouf, R. Hamacha, F. Villièras, and A. Bengueddach, "Kinetics and thermodynamics adsorption of phenolic compounds on organic-inorganic hybrid mesoporous material," International Journal of Innovation and Applied Studies, vol. 3, no. 4, pp. 1116-1124, 2013. 